\title{
THE EMPIRICAL REVIEW OF CRITICAL SUCCESS FACTORS ON THE CAUSES OF DELAY IN ROAD CONSTRUCTIONS PROJECTS IN THE GCC COUNTRIES
}

\author{
Suleiman Said Al Hinai \\ PhD Student \\ Faculty of Business and Accountancy \\ University of Selangor, Malaysia \\ E-mail: s.alhinai36yy@gmail.com \\ Dr. Abul Bashar Bhuiyan \\ Associate Professor \\ Faculty of Business and Accountancy \\ University of Selangor, Malaysia \\ E-mail: bashariuk@gmail.com \\ Dr. Setyawan Widyarto \\ Associate Professor and Dean \\ Centre for Graduate Studies \\ University of Selangor, Malaysia \\ E-mail: swidyarto@unisel.edu.my
}

\begin{abstract}
The aim of this study is to identify the critical success factors on the delays of road constructions in the GCC countries and their effects on project delivery in Arab countries. Towards the achievement of the objectives the study used the empirical literature from all relevant online sources and data based as many as possible. The findings of this study have summarized and shortlisted the success factors in the two categories such as internal and external factors have caused to be influenced to delay of road construction in the Arab regions. However, in the category of internal factors, there are 63 factors shortlisted from seven groups of factors which has revealed to effects on the delay of road constructions especially, the consultant related factors, and the contractor related factors, designed related factors, client-related factors, laborrelated factors, material related issues, equipment-related issues respectively. Moreover, external related factors are also considered to summarize especially natural disaster (flood, hurricanes, and cyclone, etc.), conflict, war, global financial crisis, compensation delay to the affected property owner, the price fluctuated, unexpected ground conditions (soil and high-water level), changing of government regulations and laws, delays in obtaining permission from the municipality, loss of time by traffic control and restrictions at the job site, the problem with the inhabitant of community, delays in providing service from utilities (water and electricity's) and accident during constructions accordingly. The present study also concluded the effects of the above factors which have delay road constructions through increasing of cost and overrun it,
\end{abstract}


taken over time, creating of disputes, going for lawsuits, finally happing of abandon of projects. Thus, the present study has given the following recommendations to overcome of above problems by increasing detailed site investigations, ensure careful monitoring and regular meetings, effective site management, collaborative working, and effective coordination's, proper and comprehensive planning and scheduling, and ensure full and intensive commitment from all parties accordingly.

Keywords: Critical Success Factors, Road Constructions Delay and Arab Countries and GCC Countries.

\section{INTRODUCTION}

The causes of delay are the main constraints to the successful completion of road construction projects in developing countries (Abdel Khalek, Aziz, \& Abdeen, 2018; Alamri, Amoudi, \&Njie, 2017). Moreover, delay causes impacts on the road constructions projects in the Sultanate of Oman (Oyegoke \& Al Kiyumi, 2017). However, the evaluation of the progress reports on the road projects constructed during the period 2011-2015 in Saudi Arabia concluded that delays are extensive: the average ratio of planned contract duration to the actual completion time is $58.24 \%$, ranging from 2\% to 172\% (Mahamid, 2011, 2013a, 2013b, 2016). On the other hand, construction delays are a common phenomenon in road construction projects in Egypt including. Therefore, it is essential to study and analyze the causes of road construction delays. They also concluded that delay causes having different types of construction, different countries, different periods, and different numbers of delay causes and delay groups (Remon Fayek Aziz, 2013; Remon F. Aziz \& Abdel-Hakam, 2016; Elawi, Algahtany, \& Kashiwagi, 2016). Studies also summarized about the construction industry is considered as one of the most important industries and It is well known that most road construction projects in this country are exposed to time and cost overrun or both Iraq (Bekr, 2015).

Moreover, studies indicated that owners rank poor communication among project participants as the top severe factor affecting the performance in construction projects, followed by poor labor productivity and poor planning and scheduling, respectively. However, contractors' point of view, concluded the most severe factor is payments delay, followed by an escalation of material prices and poor labor productivity, respectively. In case of consultant's issues, there are top three affecting by poor planning and scheduling, poor site management, and payments delay respectively (Mahamid, 2011, 2013a, 2013b, 2016, 2017). In the same way, causes of project delays were experiencing delays from 50\% to $150 \%$ in KSA (Alzara, Kashiwagi, Kashiwagi, \& Al-Tassan, 2016). However, identified the cost and time overrun allocated for this type of road project and cause critical problems for both the developer and the contractor in Jordan, which (Al-Hazim \& Salem, 2015). Another study discovered the causes of delays in road construction projects considered as investments in an unpredictable market in Lebanon (Tarhini, Fakih, Arzoky, \& Tarhini, 2015). Moreover, the delays for construction projects differ from one country to another and even between types of projects within the same geographic location (Emam, Farrell, \& Abdelaal, 2015; R. Hasan, Suliman, \& Malki, 2014).

However, Jarkas, A. M. and J. H. Younes in 2014 revealed about delays in construction projects are global phenomena and the State of Qatar is no exception. Moreover, focused on exploring the major determinants of productivity, their co-relationship, and the problem categories responsible for construction delay in the context of Oman road construction industry. Studies also summarized that owners, consultants, contractors, and foremen/workers especially 
Lack professionalism, fairness in financial transactions, incompetent supervisors, lack of materials, and incomplete drawing are found as top five factors of productivity (Emam et al., 2015; R. Hasan et al., 2014; Jarkas \& Younes, 2014). In Jordan construction industry is a major player in the economy, generating both, employment and wealth. However, many projects experience extensive delays and thereby exceed initial time and cost estimates (Sweis, Sweis, Abu Hammad, \& Shboul, 2008).

There are numerous issues and challenges are facing road construction industries in all over the countries, especially, improper contract management and some other unexpected events, so many claims and disputes are raised by the owner, consultant, and contractor each other. They are usually accompanied by cost overruns. Moreover, it is a debilitating effect on clients, contractors, and consultants in terms of growth in adversarial relationships, mistrust, litigation, arbitration, cash-flow problems, and a general feeling of trepidation towards each other. Nevertheless, it has revealed also caused and effects as time delay in construction projects, size or its experience, Large to small construction firms display a greater tendency to time delay, few found that tendency of time delay increases with the experience of the construction firm and others found the converse. There is still debate to summarized influential causes and their effects on the road construction industries. Moreover, there is a unique study has explored yet to summarized the critical factors in the area of Arab counties. Therefore, it is a significant and timely initiative to have an empirical review on critical success factors on the delay in the road construction industries in the Arab countries. Thus, this study aims to find the potential causes of construction delays and their effects on project delivery in Arab countries.

\section{EMPIRICAL REVIEW FINDINGS}

Abdelhadi, Y., et al. in 2019 examined the several delay analysis methods (DAMs) have been developed and used in the construction industry in order to analyze the causes and effects of delay events, the specific context of UAE, exploring the factors influencing their selection decisions as well as the process of making such a decision. There is a total of eight expert respondents from five different projects in the UAE were selected who provided critical insight into the decision-making process adopted in practice to select a DAM. The individual project case analysis as well as the cross-case analysis helped to identify a number of factors that influence the selection of DAMs in UAE projects. Some of the main identified factors were the attitude of the client, experience of the delay analyst, reputation and impartiality of the delay analyst, complexity of the project, and cost and timing of performing the analysis. The research argues that such an important decision process that can have a serious impact on the success of a commercial venture requires individual organizations to develop and adopt clear guidelines on how such decisions are made to protect their commercial interests (Abdelhadi, Dulaimi, \& Bajracharya, 2019). Moreover, Ahmadabadi, A. A., and G. Heravi in 2019 evaluate the effects of CSFs on the success of PPP projects using PLS-SEM. To this end, SC was monitored throughout construction, operation, and final transfer stages, whereas CSFs were taken into account during the procurement stage of the PPP project. Then, based on an opinion survey in Iran, the effects of CSFs on the success of PPP projects were evaluated based on the developed PLS-SEM model. Moreover, in order to validate the proposed model, two national highway projects in Iran were studied in detail. The results confirmed the effect of CSF on project success and showed that private sector capability has a direct effect on project success during the construction period and government capability is very effective during the project operation stage. In addition, investigating the case studies with respect to the introduced model indicated that a transparent 
bidding process, risk allocation, and good partnering are among the CSFs in PPP projects in developing countries (Ahmadabadi \& Heravi, 2019)

On the other hand, Abdel Khalek, H. A., et al. in 2018 has investigated and sorted the causes that affect batch plant productivity. To perform that goal, researchers invited experts in this field by answering detailed a questionnaire survey. It was taken brainstorming into consideration, through more effective causes was identified in batch plant. Totally, forty-five (45) related causes are classified into five (5) major groups. He did the survey was done with representatives and experts from public and private automated batch plants. Findings from the analyzed by Analytic Hierarchy Process (AHP), ranking, and simple percentages. All ranked causes were demonstrated and mentioned against their most effective causes to the batch plant productivity (Abdel Khalek, Aziz, \& Abdeen, 2018). However, Islam, M. S. and B. Trigunarsyah in 2017 explored the construction delay is one of the basic constraints to achieve the project objectives in developing countries. This study found the causes and effects of construction delays in developing countries. A thorough literature review has been done following the content analysis method. The relevant literature of 28 developing countries was collected from the scholarly journals published in the period of 2006 to 2016. The different developing countries are grouped into three geographic regions, i.e. South and Southeast Asia, the Middle East, and Africa. In these regions, a total of 53 potential causes of delay under 8 major groups is identified. The frequency and ranking of these factors have been done. The factors, delay in progress payment by the owner, contractors' cash flow problem, improper planning and scheduling, poor site management, and change order by the owner during construction, are acknowledged as critical causes of delay in developing countries. This study will assist both academic and professional experts in providing more insight into construction delays and project management in developing countries (Islam \& Trigunarsyah, 2017).

In the same way, Alamri, N., et al. in 2017 investigate and analyze the causes of delays in Dam projects in Oman. An intensive literature review was carried out to identify the causes of delays in Dam and infrastructure projects. Then, a questionnaire survey was employed to collect data from professionals involved in Dam construction projects. 60 causes of delay were integrated into the questionnaires which were grouped under four main categories: Client, Contractor, Consultant, and External Factors. The collected data were then analyzed statistically and ranked according to its significance. The results reveal, based on Pareto's law of 80/20, that the top causes behind the delays of Dam construction projects in Oman are: severe weather conditions, change orders, uncertainty in ground condition, poor site management, executive bureaucracy in the client organization, feasibility study did not cover all aspects, mistakes in soil investigation, natural effects during construction work, the difficulty of defining project requirement, slowness of decision-making process, delay of obtaining approval from the different government authorities, and land acquisition. These findings demonstrate there is an urgent necessity to tackle the project's site related causes and causes related to client and contractor (Alamri, Amoudi, \& Njie, 2017). Moreover, Gebrehiwet, T. and H. Luo in 2017 investigates the typical causes of delay at different stages of construction and its effect in the Ethiopian construction projects. Using a questionnaire with 52 causes and 5 effects of delay, data were collected from 77 participants selected based on purposive sampling from the different contracting organizations. The methodologies used in this research are the relative important index (RII) and the correlation coefficient. Based on the comparison, the impact of delay is found as, construction stage, pre-construction stage, and post-construction stage sequentially. The analysis of the relationship in the construction process shows; the average/overall is highly 
related, the construction stage is the second related, the post-construction stage is the third related, and the pre-construction stage is far part of all stages. As far as, overall/average causes of delay are comparable to all stages. So overall, the influential causes of delay investigated are corruption, unavailability of utilities at site, inflation/price increases in materials, lack of quality materials, late design and design documents, slow delivery of materials, late in approving and receiving of complete project work, poor site management and performance, late release budget/funds, and ineffective project planning and scheduling successively as unique to the Ethiopian construction project. The critical effects of delay investigated are cost overruns, time overrun, termination of the contract, arbitration, and litigation sequentially. Although the research is conducted on the Ethiopian construction projects, it can also apply to other countries and further study (Gebrehiwet \& Luo, 2017).

However, Oyegoke, A. S. and N. Al Kiyumi in 2017 identified the causes, impacts, and mitigations of delay in megaprojects in the Sultanate of Oman. Project delay is becoming a problem in the Sultanate of Oman as evidenced by many delayed projects across the country. A systematic review of the literature identifies through main stakeholders the numerous causes, impacts, and methods of mitigating delay from previous studies. A questionnaire survey on Oman was carried out to sample opinions from the practitioners; 53 questionnaires were received and analyzed using the relative importance index (RII) method. The five most frequent causes of delay in the Sultanate of Oman, in rank order, our a selection of the lowest bid, instead of best bid for the client (RII: 0.698); the financial condition of the main contractor (RII: 0.664); delay in decision-making by the client (RII: 0.656); and poor construction planning by the main contractor (RII: 0.649). Also, the findings indicate that extra cost (RII: 0.754) and project time overrun (RII: 0.724 ) are the most significant effects of the delay in the Oman megaprojects. The use of experienced contractors and consultants (RII 0.675), efficient construction planning by the main contractor, and effective site management and supervision (RII: 0.667) are essential mitigation methods of construction delay in Oman megaprojects. The study recommends threepart novel solutions to mitigate delay in the Oman construction industry (Oyegoke \& Al Kiyumi, 2017).

In the meantime, Mahamid, I. in 2017 addressed schedule delays in road construction projects in Saudi Arabia. The evaluation of the progress reports of 55 road projects constructed during the period 2011-2015 in Saudi Arabia concluded that delays are extensive: the average ratio of planned contract duration to the actual completion time is $58.24 \%$, ranging from $2 \%$ to $172 \%$. The study also investigated the main factors and effects of schedule delays in road construction projects through a questionnaire survey. There are 70 contractors working in road construction completed a structured questionnaire survey. Moreover, 34 identified factors were ranked according to their levels of severity, frequency, and importance. Results indicated that the top five important factors affecting schedule delay in road construction projects are: improper planning, poor labor productivity, additional works, rework, and lack of contractor experience. The study concluded that the main effects of schedule delay in road construction projects as assessed by contractors are: cost overrun, disputes, arbitration, litigation, and poor quality. Based on the study findings, the following recommendations were formulated: Managerial skills of construction parties should be improved, Labors' motivation system should be developed, More communication between construction parties should be done at the early project stages to minimize late changes during the construction phase, Policy of contract awarding should be improved: resources and capabilities of bidders should be checked carefully (Mahamid, 2017). 
On the other hand, Aziz, R. F. and A. A. Abdel-Hakam in 2016 analyzed the construction delays are a common phenomenon in civil engineering projects in Egypt including road construction projects. Therefore, it is essential to study and analyze the causes of road construction delays. They studied a list of construction delay causes gathered from literature having different types of construction, different countries, different periods, and different numbers of delay causes and delay groups. A questionnaire and personal interviews have formed the basis of this paper listing 293 delay causes. The questionnaire survey was distributed to 500 construction participants and 389 were received who represent consultants, contractors, and site/design engineers excluding the owner representing the government in road projects as one party only. Relative Importance Index (RII) is calculated and according to the highest values the top twenty and the least twenty delay causes of construction projects in Egypt are determined. The test results reveal a good correlation of causes and groups between contractors and site/design engineers and between consultants and site design engineers and a somewhat low correlation between contractors and consultants. So there are no root causes that can be taken for granted to be the most or least effective delay causes. A proposed model for predicting actual road construction project duration was developed; a real case study tested the accuracy of the proposed model. According to the analysis of the case study, the most contributing causes and groups to delays were discussed, and some future recommendations were proposed in order to control and minimize delays in road construction projects. These findings can be helpful for project managers to mitigate road construction delays in Egypt. In order to effectively overcome the road construction delays in developing countries, suggestions are made for fundamental and large-scale reforms in procurement systems and stakeholders' management. Also, this paper is useful for both researchers and road construction parties and allows detailed and repeatable analysis of the progress of a road construction project in order to facilitate and achieve a competitive level of time, cost, and quality for effective road construction projects (Aziz \& Abdel-Hakam, 2016).

However, Elawi, G. S. A., et al. in 2016 identifies the main causes of delay in infrastructure projects in Mecca, Saudi Arabia, and compares these with projects around the country and other Gulf countries. Data were obtained from 49 infrastructure projects undertaken by the owner and were analyzed quantitatively to understand the severity and causes of delay. 10 risk factors were identified and were grouped into four categories. The average delay in infrastructure projects in Mecca was found to be 39\%. The most severe cause of delay was found to be the land acquisition factor. This highlights the critical land ownership and acquisition issues that are prevailing in the city. Additionally, other factors that contribute to delay include contractors' lack of expertise, re-designing, and haphazard underground utilities (line services). It is concluded that the majority of project delays were caused by the owner's side as compared to contractors, consultants, and other project stakeholders. This finding matched with the research findings of the Gulf Countries Construction (GCC) Industry's literature. This study fills an important practice and research gap for improving the efficiency in delivering infrastructure projects in the holy city of Mecca and Gulf countries at large (Elawi, Algahtany, \& Kashiwagi, 2016).

Mahamid, I. in 2016 also conducted to investigate the performance in construction projects in Saudi Arabia in order to identify the contributors to poor performance and their severity according to public owners, contractors, and consultants through a questionnaire survey. Moreover, results indicate that owners rank poor communication among project participants as the top severe factor affecting the performance in construction projects, followed by poor labor productivity and poor planning and scheduling, respectively. Inputs of contractors indicate that 
the most severe factor is payment delay, followed by an escalation of material prices and poor labor productivity, respectively. Inputs of consultants underline that the top three affecting factors are: poor planning and scheduling, poor site management, and payments delay respectively. Key project participants and researchers could benefit from the findings and recommendations of this study. Although this study is related to the views of respondents from Saudi Arabia, other developing countries could benefit from its results (Mahamid, 2016). Moreover, Alzara, M., et al. in 2016 done a case study which was performed at a University campus in northern Saudi Arabia, identifying the major causes of project delays. The University was experiencing delays from $50 \%$ to $150 \%$. The delay factors were gathered from the University Projects Director. The University's delay factors were then compared to delay factors experienced on Saudi construction projects, identified by performing literature research. The comparison identified nine causes of delays that both studies documented. The study also proposes a solution to minimize the nine major delay factors. Literature research identified one construction management method, the Performance Information Procurement System (PIPS), has documented multiple times its ability to improve project performance and minimize delays (Alzara, Kashiwagi, Kashiwagi, \& Al-Tassan, 2016).

In the same way, Bekr, G. A. in 2015 summarized the construction industry is considered as one of the most important industries in Iraq. It is well known that most construction projects in this country are exposed to time and cost overrun or both. The study finds the most important causes of delay in public projects in Iraq through an intensive literature review and a survey which included a questionnaire used to assess the perceptions of the main participants involved in the construction of the projects. The questionnaire was divided into three parts. The main part focused on the causes of delay in construction sites. The 65 causes compiled through the literature review and the pilot study were classified into four groups (client-related, contractor related, consultant related and external factors). Answers were collected from 134 participants representing the three parties involved in the construction of the projects. The analysis was carried out to find the amount of delay suffered by the projects, as well as the indices related to the frequency of occurrence, severity, and importance of the four groups. In addition, a ranking of the 65 factors was carried out to identify the most crucial causes of delay. It was concluded that the most effective delay factors affecting the time overrun in the public projects in Iraq are: security measures, government change of regulations and bureaucracy, official and non-official holidays, the low performance of lowest bidder contractors in the government tendering system, design and changes by the owner, design changes by consultants, delay in progress payments by the owner, problems with the local community, owner's lack of experience in construction and economic local and global conditions (Bekr, 2015).

However, Al-Hazim, N. and Z. A. Salem in 2015 identified the most important factors that cause a delay in road construction projects in Jordan, which results in cost and time overrun allocated for this type of engineering projects and cause critical problems for both the developer and the contractor. The study also mentioned the cost at completion and that originally estimated, known as a cost overrun, can be regarded as one of the most important parameters reflecting the success of projects. In the public sector, money spent on project change orders results in increased construction time, which in return reduces the number and size of the projects that can be completed during any given fiscal year. To accomplish this goal, the documents and the final reports for various sample projects implemented over the years 2000 to 2008 were examined. All the projects were distributed by the same organization taken from the Jordan Ministry of Rural and Public Works. The outcomes of this survey can help highway officials in their conception, 
planning, programming, and project completions so that necessary actions can be selected to control these overruns in future tasks. The survey showed that 19 factors might cause delays of road construction tasks as determined through a detailed literature review. The analysis of the study indicated that the top causes affecting time and cost overrun in road construction projects in Jordan are Terrain and Weather conditions (Al-Hazim \& Salem, 2015). On the other hand, Tarhini, A., et al. in 2015 discovered causes of delays in construction projects in Lebanon. The construction projects in developing countries have priority over other projects as they are considered safe investments in an unpredictable market. Due to this prioritization, it has become increasingly important that such projects are managed in accordance with internationally accepted management best practices. Project managers of construction projects in developing countries face difficulties in effectively monitoring the progress of projects they are responsible for due to many variables. The purpose of this study is to investigate the causes of delays in the construction projects that were covered in the considered literature and conduct qualitative research to investigate their relevance by interviewing project managers of actual projects in Lebanon. Based on the literature review and from the recommendations recorded during interviews, the researcher aims to create a set of guidelines that will improve the manner in which project managers can adapt to, discover, and deal with project delays. These guidelines can be utilized as an early warning system concerning delays in construction projects (Tarhini, Fakih, Arzoky, \& Tarhini, 2015).

Moreover, Alzebdeh, K., et al. in 2015 examines interpretive structural modeling (ISM) as a viable technique for modeling complex interactions among factors responsible for cost overruns in construction projects in the Sultanate of Oman. In particular, thirteen interrelated factors associated with cost overruns were identified, along with their contextual interrelationships. Application of ISM leads to organizing these factors in a hierarchical structure which effectively demonstrates their interactions in a simple way. Four factors were found to be at the root of cost overruns: instability of the US dollar, changes in governmental regulations, faulty cost estimation, and poor coordination among project parties. Taking appropriate actions to minimize the influence of these factors can ultimately lead to better control of future project costs. This study is of value to managers and decision-makers because it provides a powerful yet very easy to apply the approach for investigating the problem of cost overruns and other similar issues (Alzebdeh, Bashir, \& Al Siyabi, 2015). Similarly, Emam, H., et al. in 2015 employed a wide variety of analytical methods to statistically conclude the most precise ranking of causes of delay. Moreover, the delays for construction projects differ from one country to another and even between types of projects within the same geographic location. The aim of this study is to examine factors contributing to delays in infrastructure projects in Qatar. A comprehensive quantitative literature review was carried out on neighboring Gulf countries. The causes of delays are identified from the literature and used in exploratory interviews with industry experts in Qatar to investigate the relevance of each cause. A survey questionnaire was prepared and was subject to pilot interviews prior to issuing it to practitioners, including clients, consultants, and contractors. Results show that over $80 \%$ of infrastructure projects suffer from the delay with an average delay of $25 \%$ and the top factors were: long response times from utility agencies; major changes in design during construction; ineffective planning and scheduling; ineffective control of progress, and; changes in the scope of projects. Construction projects need to adopt planning and scheduling methods that deal with its dynamic and changing nature to create robust programs with buffers to deal with uncertainties (Emam, Farrell, \& Abdelaal, 2015). 
Moreover, Jarkas, A. M. and J. H. Younes in 2014 revealed about delays in construction projects are global phenomena and the State of Qatar is no exception. Following the announcement of awarding the FIFA 2022 World Cup hosting rights to Qatar, the State will be spending tens of Billions of Dollars on hundreds of new construction projects. The objective of this research, therefore, is to identify, explore, and rank the relative importance of the principal factors contributing to construction delays in the local industry. To achieve this objective, a structured questionnaire survey comprising 43 delay causes, which were shortlisted based on relevant previous research on construction delay factors and the input of local industry experts and professionals, was distributed to a large number of employers, consultants, and contractors. Using the "Relative Importance Index" (RII) technique, the following causes are identified as the primary contributors to construction delays: (1) unavailability or shortage in materials; (2) delay in payment process by the employer; (3) frequent change orders issued by the employer; (4) lack of coordination among design disciplines; (5) difficulties in financing the project by the contractor; (6) late materials procurement; (7) delay in responding to requests for information; (8) clarity of drawings and technical specifications; (9) slow decision-making process by the employer; and (10) the unavailability or shortage in skilled labor and technical staff. The findings can be used to provide employers, consultants, contractors, and policymakers, guidance for focusing, acting upon, and controlling the most significant factors perceived to influence the progress of projects, hence, ameliorating the performance of the construction industry in an environment on the verge of witnessing an unprecedented boom in demand for faster delivery and lower cost of constructed facilities (Jarkas \& Younes, 2014). Bierman, B., et al. in 2014 focused on exploring the major determinants of productivity, their co-relationship, and the problem categories responsible for construction delay in the context of Oman construction industry. A semi-structured questionnaire approach is chosen as a method of the survey from the parties involved in the construction industry, such as owners, consultants, contractors, and foremen/workers. Twenty-five major factors of productivity, which are further grouped into ten critical variables by principal components analysis, are identified to be important in this study. Lack of professionalism, fairness in financial transactions, incompetent supervisors, lack of materials, and incomplete drawing are found as the top five factors of productivity. In addition, management, people, collaboration, health and safety, logistics, commitment, operational activity, authority, quality, and financial matters are reported as critical variables of productivity. Owners and consultants are determined as top problem categories for construction delay. The comparisons of the top five productivity factors found in this study to several other countries' productivity factors are also shown. Overall, this study is expected to have substantial implications for policymakers and researchers in the area of construction productivity in Oman (Bierman, O’donnell, Burke, McCormick, \& Lindsay, 2014).

However, Hasan, R., et al. in 2014 explored the factors contributing to Construction delay in road construction projects in Libya were identified and ranked through a questionnaire survey distributed to owners, consultants, and contractors involved in road projects. A total of 256 completed questionnaire forms were received and analyzed. A Structural Equation Modelling SEM Path Model of the relationship between delay factors and effects in road construction was formulated and evaluated using [SEM] 21 software. 49 factors classified into eight groups of factors and three groups of effects of delay. The contractor group in delay factors had the greatest impact on road construction delay with path coefficient $\beta$-values of 0.249 , while financial groups in delay effects had the greatest impact on road construction delay with path coefficient $\beta$-values of 0.88 . The R2 value of the model is 0.48 , indicating that the developed 
model substantially explains Construction delay. This rigorous multivariate analysis has identified several causative factors that contribute to delay in road construction projects in Libya. The findings will help all parties involved in construction projects to achieve better control over construction delays and will provide support for practitioners to incorporate risk analysis for potential Construction delays in future projects. As well as for researchers in the field of road construction and understanding of the factors causing project cost overruns in developing countries (R. Hasan, Suliman, \& Malki, 2014; U. Hasan, Whyte, \& Al Jassmi, 2019). Moreover, Emam, H., et al. in 2014 summarized the effective and efficient construction industry is of high importance to the economy of all countries. However, construction projects are notorious for overrunning time and cost. A plethora of international research has been conducted to define the causes of delay in completing projects. These studies employ a wide variety of analytical methods to statistically conclude precise rankings of causes of delay. Moreover, delays for construction projects differ from one country to another and even between types of projects within the same geographic location. This study focuses on reviewing the causes of delays within the Gulf Cooperation Council (GCC) countries. A comprehensive quantitative and qualitative literature review was carried out around previous work in GCC countries. The primary causes of delays are identified from the literature; these are then taken to exploratory interviews with industry practitioners to investigate the relevance of each cause in the context of current projects in the GCC construction industry. There are recommendations for more work around delays to projects within the region since in these expanding construction economies, research to date is relatively small (Emam, Farrell, \& Abdelaal, 2014).

Marzouk, M. M. and T. I. El-Rasas in 2014 Analyzed delay cause in Egyptian construction projects in Egypt. These problems occur frequently during the project's lifetime leading to disputes and litigation. Therefore, it is essential to study and analyze the causes of construction delays. This research presents a list of construction delay causes retrieved from the literature. The feedback of construction experts was obtained through interviews. Subsequently, a questionnaire survey was prepared. The questionnaire survey was distributed to thirty-three construction experts who represent owners, consultants, and contractor organizations. Frequency Index, Severity Index, and Importance Index are calculated, and according to the highest values of them, the top ten delay causes of construction projects in Egypt are determined. This analyzed and compared to the most important delay causes in the research. Statistical analysis is carried out using analysis of variance ANOVA method to test delay causes, obtained from the survey. The test results reveal a good correlation between groups while there is a significant difference between them for some delay causes and finally roadmap for prioritizing delay causes groups is presented (Marzouk \& El-Rasas, 2014). In the same way, Alnuaimi, A. S. and M. Mohsin in 2013 were conducted on a number of construction projects in the Muscat area to identify problems resulting from delays in the completion of construction projects. The collected data were classified into two groups of projects, the first group included projects constructed during the period 2007-2008, and the second group comprised projects constructed during the period 2009-2010. It was found that 40 percent of both groups have experienced delays in completion. Another finding was that the causes of delay are changing with the time in a pattern depending on different variables. Owner-related causes were found to be the dominant reason for the delay and contrarily the first to seek solutions (Alnuaimi \& Mohsin, 2013). 
Mahamid, I. (2013) explored the contributors to schedule delays in public construction projects in Saudi Arabia and owners' perspective. Moreover, the study identified the contributors to delays in public construction projects in Saudi Arabia from owners' viewpoint. There are 22 public owners of construction projects completed a structured questionnaire survey. The study was identified as the 35 factors through a literature review. The results indicated that the top delay contributors are: bid award for lowest price, poor site management, poor communication and coordination between construction parties, payments delay, poor labor productivity, and rework. These findings can support the Government in improving the regulations to meet the construction market needs, owners in planning and designing and evaluating policy, contractors and managers in planning and taking external and internal risks when costing and scheduling contracts, consultants in applying comprehensive contract information, and workers in conducting their day-to-day activities. Results will fill important research and practice gap and help in improving time performance in public construction projects in Saudi Arabia and other developing countries.

Mahamid, I. in 2013 explored the time, cost and quality have their proven importance as the prime measures for project success. However, the history of the construction industry worldwide is full of projects that were completed with significant time and cost overruns. This study is conducted to investigate the occurrence frequency of time overrun causes in road construction projects in the West Bank in Palestine from the contractors' viewpoint through a questionnaire survey. The field survey included 34 contractors. 52 factors affecting time overrun were identified during the research. The survey concluded that the top ten frequent factors are: segmentation of the West Bank and limited movement between areas, political situation, progress payments delay by the owner, lack of equipment efficiency, difficulties in financing project by the contractor, personal conflicts among laborers, poor communication by the consultant with other construction parties, the conflict between the contractor and other parties, award project to the lowest bid price, unreasonable project time frame by the owner (Mahamid, 2013). However, Motaleb, O. and M. Kishk in 2013 investigated further again about the causes and effects behind the delays pertaining to delivery of construction projects in the UAE. The study is exploratory in nature and incorporates a pilot questionnaire survey and interviews. An extensive literature review indicates potential factors that have possible effects on construction completion delay. The questionnaire forms were sent to 50 construction companies. Thirty-five (70\%) completed responses were received. Analysis of the survey data has revealed that about 42 potential causes and effects of delay relate to various groups of stakeholders. The results show the top fifteen factors relate to clients, project managers, and finance aspects. It was found that cost and time overruns are the most significant effects. These results are in partial agreement with previous studies. The paper argues that the key determinant in ensuring project control is on-time project delivery. The results of the study have provided moderate support for a suggested hypothesis, through a framework of project success factors. It should be of high concern to knowledge managers in various roles and decision-makers (Motaleb \& Kishk, 2013).

In the same way, Ruqaishi, M. and H. A. Bashir in 2013 examined causes of delay in construction projects in the oil and gas industry in the gulf cooperation council countries. Several studies investigating the causes of delay in projects in the construction industry have been conducted worldwide. Thus, the study investigates the causes of delay in construction projects in oil and gas processing facilities in Oman and serves as a case study for the Gulf Cooperation Council (GCC) countries. Using a questionnaire, data were collected from 59 project managers employed in different organizations in the oil and gas industry in Oman. The survey results 
showed a high degree of agreement among the perceptions of project stakeholders, clients, contractors, and consultants on the causes of project delay, and there is no evidence to suggest that the causes of project delay differ significantly according to organization size or organizational ownership. Moreover, seven factors were identified as the major causes of project delay. Although six of these identified elements are general factors that can account for the delay in any project in any industry, one of them-poor interaction with vendors in the engineering and procurement stages - is found to be unique to construction projects in the oil and gas industry. The findings of this study could be of value to organizations that are planning to conduct construction projects for oil and gas processing facilities in Oman and other nations with similar environments, such as the GCC countries (Ruqaishi \& Bashir, 2013).

Pourrostam, T. and A. Ismail in 2012 examined the causes and effects of delay in Iranian construction projects in Iran. Delays are one of the biggest problems in construction projects in developing countries, as cause negative effects on the projects. Delays can be minimized only when their causes are identified. Thus, this study identified the main causes and effects of delay in Iranian construction projects. The literature related to the field of causes and effects of delay in construction projects has been reviewed over the last decade. A questionnaire survey was conducted to solicit the causes and effect of a delay from consultants' and contractors' viewpoint. This study identified the 10 most important causes of a delay from a list of 28 different causes of delay and 6 different effects of delay. The elements of this list have identified on the basis of literature review over the last decade. The perspective of contractors and consultants has been analyzed to rank the causes of delays based on their Relative Importance Index. The 10 most causes of delay were: (1) delay in progress payment by the client, (2) change orders by the client during construction, (3) poor site management, (4) slowness in the decision-making process by client, (5) financial difficulties by contractors, (6) late in reviewing and approving design documents by client, (7) problems with subcontractors, (8) ineffective planning and scheduling of project by contractor, (9) mistakes and discrepancies in design documents, and (10) bad weather. Six major effects of delay were: (1) time overrun, (2) cost overrun, (3) disputes, (4) total abandonment (5) arbitration, and (6) litigation. The paper predicts some future trends and suggests certain areas in which future research on construction projects should be focused (Pourrostam \& Ismail, 2012).

On the other hand, Albogamy, A., et al. in 2012 has done comprehensive literature reviewed and a construction industry survey was conducted using questionnaires in KSA. There was a total of 98 out of 182 questionnaires were collected as survey data. The survey included 63 delay factors and the participants were asked to indicate their degree of importance. The causes of delay were grouped into 4 categories such as owner/client-related factors, contractor related factors, consultant related factors, and external factors. The findings of the paper suggest that the contractor and owner/client-related factors are the most critical factors that cause delay the construction projects in Saudi Arabia. After discovering the key causes, an attempt will be made in the second part of the research paper to develop a risk management framework/model to eliminate or to minimize the impact of delays in the construction projects (Albogamy, Scott, \& Dawood, 2012). Moreover, Rafieizonooz, M. in 2012 examined how to minimize the delay in Construction Projects in Tehran, Iran. Because the construction industry is one of the most profitable sectors in Iran's economy. Delay is a major common problem in construction projects in Iran. This research, by considering the main causes of delay, prepared appropriate suggestions to minimize delay in construction projects in Tehran (Capital of Iran). Literature review summary provided up to date information with current literature and based on reviewing past 
publications. The questionnaires were distributed among respondents who are involved in the construction project in Tehran, Iran. The process of data analysis and discussions were conducted based on the questionnaire survey to identify the frequency of occurrence and severity effect of delay as well as findings the most effective methods of minimizing delay in Tehran's construction projects. As a result of this study, respondents believe that delays in payment to contractors by clients, Difficulties in financing by contractors, Slowness in decision making by clients,s and Poor site management by contractors are the most frequent and severe causes of delay in Tehran construction projects. Moreover, the negative effects of delay on construction projects are: Cost overruns, Change in Schedule, and Liquidated Damage. Furthermore, the most effective methods of minimizing delay are as follows: Pay progress payment to the contractor on time' by client, Accurate initial cost and time estimates by client and contractor, Competent personnel of contractor and sub-contractor by the contractor (Rafieizonooz, 2012).

Mahamid, I. and A. Bruland in 2012 investigates the statistical relationship between the actual and estimated cost of road construction projects using data from road construction projects awarded in the West Bank in Palestine over the years 2004-2008. The study is based on a sample of 169 road construction projects. Regression models based on this data, reveal that $100 \%$ of projects suffer from cost deviation: $76 \%$ of projects are under-estimated while $24 \%$ are overestimated. The deviation between the estimated and actual cost average of $14.6 \%$, ranging from $39 \%$ to $98 \%$. The results show that the relationship between the project size (length and width of the road) and the cost deviation is very weak, the coefficient of determination R2 $=0.0028$ (Mahamid \& Bruland, 2012). In the same way, Mohsin, M. A. in 2012 evaluated the claim Analysis of Construction Projects in Oman. Because claims are one of the problems that construction project may face. Claims might cause many effects such as payment delay, the extension of time, and work suspension. From the circumstance, the present study identifies major claims in the construction industry in Oman and factors affecting these claims, as a result of the construction boom, claims get bigger attention due to the high effect on the main elements of construction management. A field study has been conducted to collect data required in claim concern. Data were collected through a data collecting form designed for this purpose, collected data was for 45 projects with specific criteria. According to the analyzed data, it's been shown that the average of claims in construction projects is 2.6 claims per project, most of these claims are: extension of time effect, solved in negotiation manner, occurred in lump sum contracts. Owners are the first party "as sources of claims" with $42 \%$ of the research sample over other sources like consultants, contractors, and contract documents (Mohsin, 2012). Moreover, Mahamid, I., et al. 2011 examined to explore the causes of delay in road construction projects in the West Bank in Palestine. He has summarized the review that the construction delay is considered to be one of the most recurring problems in the construction industry and it has an adverse effect on project success in terms of time, cost, quality, and safety. This study finally conducted an investigation on the time performance of road construction projects in the West Bank in Palestine to identify the causes of delay and their severity according to contractors and consultants through a questionnaire survey. The field survey included 34 contractors and 30 consultants. A total of 52 causes of delay were identified during the research. The survey concluded that the top five severe delay causes are political situation, segmentation of the West Bank and limited movement between areas, award project to the lowest bid price, progress payment delay by the owner, and shortage of equipment (Mahamid, 2011). 
Jurf, N. A. and S. Beheiry in 2010 found the Cost and schedule deviation from the estimated baseline are common in construction projects and have a negative effect on construction activity, which is a substantial portion of the GDP in most countries. Previous research studies examined the causes of deviation in several countries including some Gulf Council Countries (GCC) like Kuwait and the UAE, but none were done on the sizeable Qatari market. Qatar is expected to require an additional 93,000 residential units by the end of 2010 [1] to sufficiently address the rising demand, as a result of rapid population increase relative to supply [2]. Therefore, this study identified and ranked, using the Relative Importance Index (RII) method, the significant factors influencing cost and schedule deviation in Qatari residential compound projects. A detailed questionnaire was developed on a Likert scale addressing these factors and was used to solicit the viewpoints of Grade A contractors. The collected project sample had a total capital investment of approximately $\$ 1.25$ Billion and the projects were executed within a five year period (2000 - 2005). The study revealed that most contractors viewed material delays as the most prominent issue influencing construction project predictability in Qatar. Other top ten factors included design changes, labor shortages, deficient estimates and cash flow planning (Jurf \& Beheiry, 2010). However, Motaleb, O. and M. Kishk in 2010 investigated the causes and effects of construction delays in the UAE. The major criticism of the United Arab Emirates (UAE) construction companies is the growing rate of delays in project delivery. The study underpins investigating the causes and effects of construction project delays in the UAE. The study was based on a literature review and a questionnaire survey that investigated 42 potential delay factors. Questionnaires were sent to 50 companies with a response rate of $70 \%$. Typical results have shown that change orders, financial and other client-related factors are the most significant causes of delay. Besides, cost and time overruns are the most significant effects. These results are in partial agreement with previous studies. However, some of the results are surprising and have implications regarding the need of training clients and their representatives but also project teams (Motaleb \& Kishk, 2010).

Alnuaimi, A. S., et al. in 2009 discussed variations in public construction projects in Oman by investigating causes of variations, studying their effects on the project, identifying the beneficial parties, and suggesting remedies to alleviate related problems. Tasks included an analysis of four actual case studies and conducting a field survey via a questionnaire. It was determined that the client's additional works and modifications to design were the most important factors causing change orders, followed by the nonavailability of construction manuals and procedures. The most important effects of change orders on the project were found to be the schedule delays, disputes, and cost overruns. The contractor was found to be the party most benefiting from the change orders followed by the consultant and then the client. A set of remedial actions were suggested and respondents viewed that the revision of registration of consulting offices would be the most important action followed by establishing standard documents for design procedures and building a national database about soil conditions and services (Alnuaimi, Taha, Al Mohsin, \& Al-Harthi, 2009). In the same way, Enshassi, A., et al. in 2009 assessed the factors leading to time overruns (delays) and cost overruns in construction projects in the Gaza Strip. Since there appear to be additional special contributors to delays here, the relative perceptions of contractors, consultants and owners are compared, based on a listing of causal factors derived from previous studies elsewhere, together with other factors arising from special conditions in the Gaza Strip. A survey of randomly selected samples yielded responses from 66 contractors, 27 consultants, and 31 owners. The survey included 110 delay factors/causes which were grouped into 12 major groups. The same survey also included 42 cost 
overrun factors. The level of importance of the delays and cost overrun factors were measured and ranked by their importance indexes, according to the perspectives of contractors, consultants, and owners. There seems to be a general agreement between contractors, consultants, and owners regarding the causes of delays and cost overruns. The main four causes of time delays included strikes and border closures, material-related factors, lack of materials in markets, and delays in materials delivery to the site. Additionally, the main three causes for cost overruns included price fluctuations of construction materials, contractor delays in material and equipment delivery, and inflation. The outcome of this paper will assist owners, contractors, and consultants in understanding the reasons for delays and cost overruns, thus eliminating or minimizing these causes. This could be achieved by better management of the projects and by finding new methods for storing the critical materials from the beginning of the project. Furthermore, the local government is advised to initiate legislation to overcome problems arising from monopolies in the supply of construction materials (Enshassi, Al-Najjar, \& Kumaraswamy, 2009).

Moreover, Asnaashari, E., et al. in 2009 mentioned that the delay is one of the most reoccurring problems in the construction industry and has negative impacts on project success in terms of time, cost, quality, and safety. They identified the most significant causes of delay is vital. The construction industry in Iran, with an annual turnover of US\$ 38.4 billion, is one of the most profitable sectors in the country. Finally, they have done an investigation into factors which cause construction delay. The first part was focused on the role of Stakeholders, Politics, and the Economy in causing delays in projects. The second part will focus on the causes of delays associated with Project Management, Logistics, Technology, and the Environment. Eleven indepth interviews were conducted with construction managers and practitioners associated with the Iranian construction industry. Interviewees, with more than 10 years' experience, explained the factors that cause a delay in the construction industry in Iran. Responses were analyzed qualitatively and a comprehensive interpretation was developed. The results revealed that most construction projects in Iran are subject to delay. Traditional management style, poor scheduling, using old technology, purchasing problems, low level of commitment among supply chain members, storage issues, and poor weather conditions are the top causes of delays in the Iranian construction industry (Asnaashari, Knight, Hurst, \& Farahani, 2009). In general, Tumi, S. A. H., et al. in 2009 examined the causes of delay in the construction industry in Libya. As the delays are one of the biggest problems construction firms face. Delays can lead to many negative effects such as lawsuits between owners and contractors, increased costs, loss of productivity and revenue, and contract termination. Even though various studies have been considered into the causes affecting delays, these studies seldom discuss common and general causes of delays in construction projects. Thus, a comprehensive study on these delays is essential. Since the problems are rather contextual, the study needs to focus on specific causes of delay like insufficient coordination and ineffective communication between involved parties in construction projects located at Benghazi City in Libya. Literature review and a questionnaire survey targeted at construction projects in Libya's country and have been used as the tools to carry out this study. This paper presents the findings of a survey aimed at identifying some of the most important causes of delays in construction projects in the above-mentioned city. It is hoped that these findings will guide efforts to enhance the performance of the construction Industry. This paper also explores and provides some guidelines and actionable information that can be led to enhance the construction process (Tumi, Omran, \& Pakir, 2009). 
Al-Najjar, J. M. in 2008 assessed factors influencing time and cost overruns on construction projects in Gaza Strip. The objectives of the study were achieved through two approaches, the first one was a valid questionnaire that was obtained from contracting companies, consultants, and owners in Gaza Strip. The second by studying five cases with five projects exposed to time and cost overrun. The study clarified that "Strikes, Israeli attacks, and border closures" was the most critical factor that influences project delay. The survey also indicated that "material- related factors" occupied the second rank in importance, were "the lack of materials in markets" and "delay in materials delivered to the site" were among the most important factors affecting delay. The study also illustrated that "price fluctuations of construction materials" which was due to border closure was one of the most important factors that may lead to cost overrun. Also, it clarified that the contractor's delay of material delivery and equipment has led to cost overrun. The study also clarified that price inflation highly contributes to cost overrun. The study recommended owners, contractors, and consultants to hold their responsibilities to avoid any delay or cost overrun which could be achieved by good management of the project and finding new methods for storing the needed materials from the beginning of the project. The study also recommended the government to adopt laws through the Palestinian legislative council to prevent materials monopoly. Also, it recommended the government with the necessity of dealing with new entrances such as Rafah entrance to guarantee material transfer into the Gaza Strip (AlNajjar, 2008). Moreover, Sweis, G., et al. in 2008 determined delays in construction projects in Jordan. As the construction industry is a major player in the economy, generating both, employment and wealth. However many projects experience extensive delays and thereby exceed initial time and cost estimates. A host of causes of construction delays in residential projects were identified and classified according to Darwin's Open Conversion System. The most common causes were evaluated by using both, the data collected in a survey conducted to residential projects consultant engineers, contractors, and owners, and interviews with senior professionals in the field. Most correspondents agreed that financial difficulties faced by the contractor and too many change orders by the owner are the leading causes of construction delay. Severe weather conditions and changes in government regulations and laws ranked among the least important causes (Sweis, Sweis, Abu Hammad, \& Shboul, 2008).

However, Assaf, S. A. and S. Al-Hejji in 2006 has done a survey on-time performance of different types of construction projects in Saudi Arabia was conducted to determine the causes of delay and their importance according to each of the project participants, i.e., the owner, consultant and the contractor. The field survey conducted included 23 contractors, 19 consultants, and 15 owners. Seventy-three cases of delay were identified during the research. $76 \%$ of the contractors and $56 \%$ of the consultants indicated that the average time overrun is between $10 \%$ and $30 \%$ of the original duration. The most common cause of delay identified by all three parties is "change order". Surveys concluded that $70 \%$ of projects experienced time overrun and found that 45 out of 76 projects considered were delayed (Assaf \& Al-Hejji, 2006). Moreover, Faridi, A. S. and S. M. El-Sayegh in 2006 summarized the construction delay is considered one of the most recurring problems in the construction industry. Delays have an adverse impact on project success in terms of time, cost, quality and safety. The effects of construction delays are not confined to the construction industry only, but influence the overall economy of a country like UAE, where construction plays a major role in its development and contributes $14 \%$ to the GDP. Thus, it is essential to define the most significant causes of delay in order to avoid or minimize their impact on construction projects. A detailed questionnaire was developed and used to get input from professionals associated with the UAE construction 
industry. The perspective of contractors and consultants has been analyzed to rank the causes of delays based on their Relative Importance Index. Contractors and consultants were in agreement on the most significant causes of delays. The research revealed that $50 \%$ of the construction projects in the UAE encounter delays and are not completed on time. The top 10 most significant causes of construction delays have been identified by this research. Approval of drawings, inadequate early planning, and slowness of the owners' decision-making process are the top causes of delay in the UAE construction industry (Faridi \& El-Sayegh, 2006).

Al Tabtabai, H. M. in 2002 analyzed and ranked the causes of delays in building and housing type projects undertaken by governmental agencies in Kuwait. The study was based on a survey with the parties involved in these governmental projects. A questionnaire containing 53 delay causes was distributed and the respondents were 23 governmental management and engineering personnel, 17 contractors, and 8 designers representing $\mathrm{A} / \mathrm{E}$ firms. The questions were prepared in which the causes were categorized into eight major groups: 1) client administration and organizational, 2) client's site supervision, 3) contractor related, 4) laborrelated 5) quality-related, 6) design related, 7) project management, and 8) contractually related. The factors were measured and ranked under each group by the 'Relative Importance Index' for three parties. The results suggest that delays are attributed to poor project management factors and client's administration and site supervision practices. The paper presents recommendations for a better application of project management techniques and procedures being taken at both conceptual and detailed planning phases of projects (Al Tabtabai, 2002). Al-Momani, A. H. in 2000 investigated to identify the causes of delays on 130 public projects in Jordan and to aid construction managers in establishing adequate evaluation prior to the contract award using quantitative data. Projects investigated in this study included residential, government agency and government buildings, school buildings, medical centers, and communication installations. The major effects of this study indicate the principal cases of delay in construction of public projects relate to designers, user changes, atmospheric conditions, site conditions, late deliveries, economic conditions, and increase in amount. The presence of these factors has an impact on the successful completion of the projects at the time contractually specified. The findings suggest that extra attention to factors identified in this field will help industry practitioners in minimizing the risk of contract conflicts (Al-Momani, 2000). Mezher, T. M. and W. Tawil in 1998 found the presents the major causes of delays in the construction industry in Lebanon and the relative importance of these postponements. A survey of a randomly selected sample of 11 owners, 15 contractors, and 10 architectural/engineering (A/E) firms from Lebanon was undertaken. The survey included 64 causes of delay, grouped into 10 major groups, in which the participants were asked to indicate their level of importance of each delay. The level of importance of the causes and the groups were measured and ranked by the importance index for owners, contractors, and $\mathrm{A} / \mathrm{E}$ firms. It was found that all three parties generally agreed on the ranking of the major categories of delay factors. Owners had more concerns with regard to financial issues, while contractors ranked contractual relationships highest, and finally, A/E firms ranked project management highest (Mezher \& Tawil, 1998).

\section{CONCLUSION AND RECOMMENDATIONS}

This study aims to find the potential causes of construction delays and their effects on project delivery in Arab countries. Thus, the present study summarized and shortlisted the factors in the two categories such as internal and external factors have caused to be influenced to delay of road construction in the Arab regions. However, in the category of internal factors, there are a group 
of factors, consultant related factors are effects on the delay of projects, in case of delaying of approval, inaccurate site investigations and delay inspections, inadequate project management assistance, lack of experiences, late reviewing and approval of the design, poor communications and coordination's and conflicting consultant vs design engineer respectively. Moreover, the contractor related factors also revealed to cause to delay of road projects by delaying of payment, insufficient projects planning and scheduling, inadequate experiences contractors, poor site management and supervisions, incompetent project team, inappropriate constructions methods, obsolete technology, unreliable subcontractors, frequent changes of subcontractors, poor communications and coordination's with other parties and rework due to errors accordingly. On the other hand, designed related factors are also caused to delay road projects by insufficient data collections and survey before design, design errors, mistakes and delay in producing of design documents, poor use of advanced engineering software, the complexity of project design, unclear and inadequate details in design drawing and misunderstand of client requirements by designer accordingly. In the same way, labor-related factors are also caused to delay of the project by low productivity of labor, unqualified and inadequate experiences, low motivation and moral, shortages of labor, absenteeism, slow mobilizations labor, labor sticks and personal conflicts among labor respectively. However, in case of material related issues also identified which has caused to delay road constructions by lack of reliable supplier, escalations of materials prices, poor quality of constructions materials, late delivery of materials, shortage of constructions materials, poor procurement of constructions materials, changes of materials types and specifications and damage of materials etc. Similarly, equipment-related issues are considered to find caused to delay of road construction by inadequate modern equipment's, low efficiency of equipment, shortage of equipment, slow mobilizations of equipment, frequent equipment breakdown, equipment allocations problem and improper equipment respectively.

In terms of external related factors are also considered to summarize and list out which has caused to delay of road constructions in the Arab regions. Especially natural disaster (flood, hurricanes, and cyclone, etc.), conflict, war, global financial crisis, compensation delay to the affected property owner, the price fluctuated, unexpected ground conditions (soil and high-water level), changing of government regulations and laws, delays in obtaining permission from the municipality, loss of time by traffic control and restrictions at the job site, the problem with an inhabitant of community, delays in providing service from utilities (water and electricity's) and accident during constructions respectively. The present study also concluded the effects of the above factors which have delay road constructions through increasing of cost and overrun it, taken over time, creating of disputes, going for lawsuits, finally happing of abandon of projects. Thus, the present study has given the following recommendations to overcome of above problems by increasing detailed site investigations, ensure careful monitoring and regular meetings, effective site management, collaborative working, and effective coordination's, proper and comprehensive planning and scheduling and ensure full and intensive commitment from all parties accordingly.

\section{REFERENCES}

Abdel Khalek, H. A., Aziz, R. F., \& Abdeen, A. H. (2018). Identify and prioritize the major influencing causes of automated concrete mixing system for mega construction projects using analytic hierarchy process. Alexandria Engineering Journal, 57(4), 3451-3461. doi:https://doi.org/10.1016/j.aej.2018.04.003 
Abdelhadi, Y., Dulaimi, M. F., \& Bajracharya, A. (2019). Factors influencing the selection of delay analysis methods in construction projects in UAE. International Journal of Construction Management, 19(4), 329-340. doi:10.1080/15623599.2018.1435155

Ahmadabadi, A. A., \& Heravi, G. (2019). The effect of critical success factors on project success in Public-Private Partnership projects: A case study of highway projects in Iran. Transport Policy, 73, 152-161. doi:10.1016/j.tranpol.2018.07.004

Al-Hazim, N., \& Salem, Z. A. (2015). Delay and cost overrun in road construction projects in Jordan. International Journal of Engineering \& Technology, 4(2), 288.

Al-Momani, A. H. (2000). Construction delay: a quantitative analysis. International Journal of Project Management, 18(1), 51-59.

Al-Najjar, J. M. (2008). Factors influencing time and cost overruns on construction projects in the Gaza Strip. Factors Influencing Time and Cost Overruns on Construction Projects in the Gaza Strip.

Al Tabtabai, H. M. (2002). Causes for delays in construction projects in Kuwait.

Alamri, N., Amoudi, O., \& Njie, G. (2017). Analysis of construction delay causes in dams projects in Oman. European Journal of Business and Social Sciences, 6(2), 19-42.

Albogamy, A., Scott, D., \& Dawood, N. (2012). Addressing construction delays in the Kingdom of Saudi Arabia. International Proceedings of Economics Development \& Research, 45, 148-153.

Alnuaimi, A. S., \& Mohsin, M. (2013). Causes of delay in completion of construction projects in Oman. Paper presented at the International Conference on Innovations in Engineering and Technology.

Alnuaimi, A. S., Taha, R. A., Al Mohsin, M., \& Al-Harthi, A. S. (2009). Causes, effects, benefits, and remedies of change orders on public construction projects in Oman. Journal of construction engineering and management, 136(5), 615-622.

Alzara, M., Kashiwagi, J., Kashiwagi, D., \& Al-Tassan, A. (2016). Using PIPS to Minimize Causes of Delay in Saudi Arabian Construction Projects: University Case Study. Procedia Engineering, 145, 932-939. doi:10.1016/j.proeng.2016.04.121

Alzebdeh, K., Bashir, H., \& Al Siyabi, S. (2015). Applying interpretive structural modeling to cost overruns in construction projects in the sultanate of Oman. The Journal of Engineering Research [TJER], 12(1), 53-68.

Asnaashari, E., Knight, A., Hurst, A., \& Farahani, S. S. (2009). Causes of construction delays in Iran: project management, logistics, technology and environment. Paper presented at the Procs 25th Annual ARCOM Conference. 
Assaf, S. A., \& Al-Hejji, S. (2006). Causes of delay in large construction projects. International Journal of Project Management, 24(4), 349-357.

Aziz, R. F. (2013). Ranking of delay factors in construction projects after Egyptian revolution. Alexandria Engineering Journal, 387-406. doi:https://doi.org/10.1016/j.aej.2013.03.002

Aziz, R. F., \& Abdel-Hakam, A. A. (2016). Exploring delay causes of road construction projects in Egypt. Alexandria Engineering Journal, 55(2), 1515-1539. doi:10.1016/j.aej.2016.03.006

Bekr, G. A. (2015). Causes of delay in public construction projects in Iraq. Jordan Journal of Civil Engineering, 159(3091), 1-14.

Bierman, B., O’donnell, J., Burke, R., McCormick, M., \& Lindsay, W. (2014). Construction of an enclosed trough EOR system in South Oman. Energy Procedia, 49, 1756-1765.

Elawi, G. S. A., Algahtany, M., \& Kashiwagi, D. (2016). Owners' Perspective of Factors Contributing to Project Delay: Case Studies of Road and Bridge Projects in Saudi Arabia. Procedia Engineering, 145, 1402-1409. doi:10.1016/j.proeng.2016.04.176

Emam, H., Farrell, P., \& Abdelaal, M. (2015). Causes of delay on infrastructure projects in Qatar. Paper presented at the Proceedings of the 31st Annual ARCOM Conference, Lincoln, UK, Association of Researchers in Construction Management, Nottingham, UK.

EMAM, H., FARRELL, P., \& ABDELAAL, M. A. (2014). Causes of delay in GCC construction projects. Smart, Sustainable and Healthy Cities, 607.

Enshassi, A., Al-Najjar, J., \& Kumaraswamy, M. (2009). Delays and cost overruns in the construction projects in the Gaza Strip. Journal of Financial Management of Property and Construction, 14(2), 126-151.

Faridi, A. S., \& El-Sayegh, S. M. (2006). Significant factors causing delay in the UAE construction industry. Construction Management and Economics, 24(11), 1167-1176.

Gebrehiwet, T., \& Luo, H. (2017). Analysis of Delay Impact on Construction Project Based on RII and Correlation Coefficient: Empirical Study. Procedia Engineering, 196, 366-374. doi:10.1016/j.proeng.2017.07.212

Hasan, R., Suliman, S. M., \& Malki, Y. A. (2014). An investigation into the delays in road projects in Bahrain. International Journal of Research in Engineering and Science, 2(2), $38-47$.

Hasan, U., Whyte, A., \& Al Jassmi, H. (2019). Critical review and methodological issues in integrated life-cycle analysis on road networks. Journal of Cleaner Production, 206, 541558. doi:https://doi.org/10.1016/j.jclepro.2018.09.148 
Islam, M. S., \& Trigunarsyah, B. (2017). Construction delays in developing countries: a review. Journal of Construction Engineering and Project Management, 7(1), 1-12.

Jarkas, A. M., \& Younes, J. H. (2014). Principle factors contributing to construction delays in the State of Qatar. International Journal of Construction Project Management, 6(1), 39.

Jurf, N. A., \& Beheiry, S. (2010, 30 March-1 April 2010). Qatar residential construction projects. Paper presented at the 2010 Second International Conference on Engineering System Management and Applications.

Mahamid, I. (2011). Risk matrix for factors affecting time delay in road construction projects: owners' perspective. Engineering, Construction and Architectural Management, 18(6), 609-617.

Mahamid, I. (2013a). Contributors to schedule delays in public construction projects in Saudi Arabia: owners' perspective. Journal of Construction Project Management and Innovation, 3(2), 608-619.

Mahamid, I. (2013b). Frequency of time overrun causes in road construction in Palestine: Contractors' view. Organization, technology \& management in construction: an international journal, 5(1), 720-729.

Mahamid, I. (2016). Factors contributing to poor performance in construction projects: studies of Saudi Arabia. Australian Journal of Multi-Disciplinary Engineering, 12(1), 27-38. doi:10.1080/14488388.2016.1243034

Mahamid, I. (2017). Schedule delay in Saudi Arabia road construction projects: size, estimate, determinants and effects. Int J Arch Eng Constr, 6(3), 51-58.

Mahamid, I., \& Bruland, A. (2012). Cost deviation in road construction projects: The case of Palestine. Australasian Journal of Construction Economics and Building, The, 12(1), 58.

Marzouk, M. M., \& El-Rasas, T. I. (2014). Analyzing delay causes in Egyptian construction projects. Journal of advanced research, 5(1), 49-55.

Mezher, T. M., \& Tawil, W. (1998). Causes of delays in the construction industry in Lebanon. Engineering, Construction and Architectural Management, 5(3), 252-260. doi:10.1108/eb021079

Mohsin, M. A. (2012). Claim Analysis of Construction Projects in Oman.

Motaleb, O., \& Kishk, M. (2010). An investigation into causes and effects of construction delays in UAE. Paper presented at the Procs 26th Annual ARCOM Conference. 
Motaleb, O., \& Kishk, M. (2013). An investigation into the risk of construction projects delays in the UAE. International Journal of Information Technology Project Management (IJITPM), 4(3), 50-65.

Oyegoke, A. S., \& Al Kiyumi, N. (2017). The causes, impacts and mitigations of delay in megaprojects in the Sultanate of Oman. Journal of Financial Management of Property and Construction, 22(3), 286-302.

Pourrostam, T., \& Ismail, A. (2012). Causes and effects of delay in Iranian construction projects. International Journal of Engineering and Technology, 4(5), 598.

Rafieizonooz, M. (2012). Minimizing Delay in Construction Projects in Tehran, Iran. Universiti Teknologi Malaysia.

Ruqaishi, M., \& Bashir, H. A. (2013). Causes of delay in construction projects in the oil and gas industry in the gulf cooperation council countries: a case study. Journal of Management in Engineering, 31(3), 05014017.

Sweis, G., Sweis, R., Abu Hammad, A., \& Shboul, A. (2008). Delays in construction projects: The case of Jordan. International Journal of Project Management, 26(6), 665-674. doi:https://doi.org/10.1016/j.ijproman.2007.09.009

Tarhini, A., Fakih, M., Arzoky, M., \& Tarhini, T. (2015). Designing guidelines to discover causes of delays in construction projects: The case of lebanon.

Tumi, S. A. H., Omran, A., \& Pakir, A. H. K. (2009). Causes of delay in construction industry in Libya. Paper presented at the The International Conference on Economics and Administration.

\section{Copyrights}

Copyright for this article is retained by the author(s), with first publication rights granted to the journal. This is an open-access article distributed under the terms and conditions of the Creative Commons Attribution license (http://creativecommons.org/licenses/by/4.0/) 